\title{
THE RIGHT TOOLS FOR THE JOB: DISCIPLINE-SPECIFIC LANGUAGE-LEARNING FOR FIRST-YEAR INTERNATIONAL ENGINEERING STUDENTS
}

\author{
John Pringle ${ }^{l}$ and Gabriel Potvin ${ }^{1,2}$ \\ ${ }^{1}$ Vantage College, University of British Columbia \\ ${ }^{2}$ Department of Chemical and Biological Engineering, University of British Columbia \\ john.pringle@ubc.ca, gabriel.potvin@ubc.ca
}

\begin{abstract}
Vantage College at UBC offers specialized first-year programs for international students that integrate core disciplinary courses with complementary language education to allow students to develop their communication skills before joining their direct-entry counterparts for the remainder of their studies. This paper builds on the partnership between two first year engineering chemistry courses and their adjunct language courses, in which the instructors work closely together to accomplish mutual learning objectives. As a measure of the effectiveness of this integrated approach on the development of discipline-specific communication skills, the frequency of specific language error types are tracked in student's lab reports, across two terms, and students report through a survey their perception of how this integrated approach helped them develop their technical communication skills. Overall, as indicated by both significant reductions in the frequency of several error types, as well as the responses provided by students, this integrated approach is effective, and the data suggests key areas of focus for further improvement.
\end{abstract}

Keywords: First-Year Education, International Students, Content Integration, Technical Communication

\section{INTRODUCTION}

Vantage College (VC) at the University of British Columbia (UBC) was established with a mandate to offer innovative interdisciplinary first-year programs to international students that integrate core content courses with discipline-specific language instruction and support. These programs are offered to international students who are in excellent academic standing but whose language proficiency level falls just below that set forth by UBC for direct entry into its programs. Participants take all of their first- year courses with their Vantage cohort, and, upon successful completion of the program, are considered to have met UBC's academic and language proficiency requirements, and join their "direct-entry" counterparts in second year for the remainder of their undergraduate studies.

In the Applied Science stream of VC, each content (engineering) course is associated with a dedicated language course, with the engineering and language instructors working closely together to develop and deliver their respective curricula and accomplish mutual learning objectives. The logistics and outcomes of this approach for a partnership between two engineering chemistry courses (APSC 182 and 183) and their associated language course (VANT 140) were presented in previous work $[6,7]$. This paper builds on this work to further study the effectiveness of specific implementations of this integrated approach.

In engineering programs, there is often a general lack of enthusiasm by students regarding language-oriented courses, and the opinion that they are less important than technical courses is often expressed, despite the lack of communication skills being one of the biggest weaknesses of engineering graduates, as identified by employers [3,5]. To make the language component of $\mathrm{VC}$ as relevant and useful to the students taking APSC 182 and 183, the latest iteration of VANT 140 focused on technical lab reports as one of the key language-related deliverables in science and engineering. The course was designed to help students build their discipline-specific language ability, through which they develop their understanding of, and familiarity with, the different components of the lab report genre.

As part of the engineering courses, students had to perform experiments and write ten lab reports over the course of the academic year. Six of these reports (3 per term) were submitted to the engineering instructor, to be evaluated for technical merit and critical analysis, and also to the language instructor, for the language to be assessed. The language instructor annotated student reports with error codes corresponding to both common and genre-specific language error types; these annotated reports were returned to students, and the students had the opportunity to revise their reports based on the provided 
feedback, and re-submit them. Both the first draft and revised submissions were marked as part of the grade for the language course.

This paper consists of two sections. The first provides an assessment of the effectiveness of this VC integrated approach to the development of academic writing skills by tracking the frequency of common linguistic and genre-specific error types in student lab reports throughout the academic year, as prepared for the aforementioned engineering chemistry courses. This data serves as an objective indicator of the effectiveness of the pedagogical approach in developing disciplinary communication skills, independently of students' perception of its effectiveness. The second part of the paper presents the results of a survey given to the current cohort of Vantage students to gauge their opinion of the language interventions, as well as identify the specific language-oriented learning tasks that they found most useful. This information provides information on students' perception of the value of the integrated approach, and can be directly compared to the results of the error frequency analysis to determine whether students' progress and their perception of their progress match, all of which can be used to improve future iterations of the course, and make this language-oriented learning more relevant to students. The survey questions presented here are a subset of a larger survey on student motivation to develop communication skills, which is presented in other work [8].

\section{RESULTS AND DISCUSSION}

\subsection{Instructional Approach and Overall Student Performance}

The overall score of both the first draft and revised version (as assessed by the language instructor) of the six reports having undergone that process, were tabulated for six students chosen at random, and the results are shown in Figure 1. Results suggest on ongoing and sustained improvement in technical writing ability, with the average grades for first drafts rising from $57 \%$ to $72 \%$ (over two terms), while revised texts improved from $69 \%$ to an average of $83 \%$ for the final two. The discontinuity in the data for revised reports is explained by the fact that only five reports underwent the usual revision process, with the reports for lab 4 being used instead in a peer evaluation task. The improvement in grade between the first draft and revision of the same report is satisfying but not entirely surprising. Assuming that the students attend to all feedback and have the ability to correct errors once they are alerted to them, grade improvement is likely since the grader is specifically looking for the ability to correct. More significant is that the average grade for first drafts rises over the course of 6 reports, indicating a reduction in number of initial errors. This points to the application of improved drafting and self-editing abilities to a new text, although admittedly of the same genre. The drop in average grade on report 2 can be attributed to marking duties being assumed by a teaching assistant. Although the error identification and annotation were comprehensive and correct, the grade awarded was lower than that which the language instructor would have given. This was addressed by further grading calibration and training, and later by the introduction of an improved grading rubric.

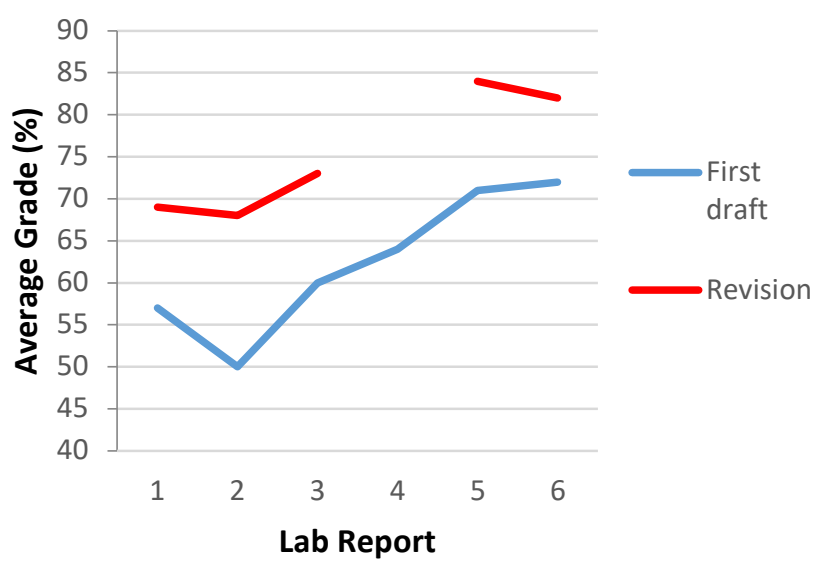

Figure 1: Average grade of first drafts and revised versions of 6 lab reports, as assessed by the language instructor. The data represents the average of 6 students, randomly selected from the class roster.

Ideally, comprehensive written corrective feedback would be given on every lab report, both first and revised draft, produced by every student. However, given the size of the cohort ( 88 students) and the number of lab reports (6 first drafts and 5 revised drafts), the time required from the language instructor to accomplish this would not be sustainable. Therefore, an indirect corrective feedback approach, using error codes, was adopted. This form of indirect written corrective feedback has been shown to be effective in improving academic writing skills, particularly among more advanced language learners [1]. During grading, each error that is identified by the instructor is highlighted and annotated with a two or three-letter code, corresponding to the particular error type (for example, VT is a verb tense error, ART is an article error, etc.). This particular coding system was developed by the language instructor with reference to the language features of the lab report genre and thus the kind of errors which are most likely to result in an unsuccessful text, and also to correspond to the foundational academic language curriculum that the students encounter in other language courses. Thus, CL (for claim) would highlight a point where the student writer has presented a possible finding, but a lack of hedging results in a claim that is too strong and not fully supported by the evidence. For 
example, a student might write 'The unidentified metal is titanium', yet the experimental evidence presented is insufficient to make such an unequivocal claim. A corrected version could be 'The unidentified metal may be titanium'. The students had learned about the importance of such interpersonal positioning and the related language features in their foundational academic English course.

Such codified error annotation lends itself to a longitudinal quantitative analysis. Accordingly, six students (from the cohort of 88) were randomly chosen. All of their first draft reports (six each) were then analyzed to tabulate the total number of specific errors. Although by no means comprehensive, this initial tabulation does present some interesting indications and suggests a direction for further study. The errors chosen for analysis were verb tense (VT), verb form (VF), passive voice (AP), self-mention (SF), claim (CL), and articles (ART). Verb form is highlighted separately from tense as the writer may use the correct tense but omit an auxiliary verb or use incorrect irregular past tense form, for example.

These particular errors were chosen as they affect not only general academic writing quality but also the generic requirements of a lab report in the applied sciences. Poor control of tense, for example, can be regarded as a global error that can affect the overall comprehensibility of a stretch of text [2]. In a lab report, tense varies across the report: the Materials and Methods section is written in the simple past passive as it recounts a series of actions that have been completed at an earlier point in time, while the Results would be described with simple present, based on the scientific assumption that the same experiment under the same conditions will always produce the same results. Thus students need to display not just mechanical control over tense formation but understand and display appropriate use. Use of simple present in the Materials and Methods section, for example, although grammatically correct, would be highlighted with 'VT'.

Students are expected, in the writing guidelines issued by the engineering instructor, to write in the passive voice throughout. By foregrounding the objects involved in the lab (equipment, processes, and results) the report is realizing scientific objectivity, and a concomitant reduction in the importance placed on the agent performing the experiment. From a linguistic perspective, the students are developing control over an academic register which focusses less on people (associated with a more natural, colloquial register) than on things, usually expressed as nouns or noun groups; for example, 'I measured the solution' as opposed to 'Measurements were taken ...'. Use of the passive voice is closely related to self-mention (use of personal pronouns or a term like 'the experimenter') and switching from active to passive will usually correct both errors; they are annotated separately, however, as self-mention can exist in a 'by' phrase even though the passive is used: 'Measurements were taken by the researchers'.

Lack of hedging when making claims, as discussed above, positions the student writer as a novice scientist who cannot yet control 'a judicious balance of tentativeness and assertion, and the expression of a suitable relationship to one's data, arguments and audience' [4]. Claims are too strong where there is a lack of modality (may, might, can etc.) and poor control of adverbial and adjectival resources for moderating strength of claim (possibly, possible etc.). When discussing results, students are expected to account plausibly for any errors or deviations from theoretical and published results. Since accounting for possible divergences is necessarily speculative, an over-confident assertion of cause disrupts the expected register. Errors in the use of articles were also tracked. This tends to be an area of difficulty in English as a second language writing and article use had been explicitly taught in term 1 of the academic year.

\subsection{Error Frequency Analysis}

The data presented below is currently limited to the analysis of 36 reports. Measuring error reduction is complicated somewhat by the collaborative nature of lab report production: students do the lab in pairs, and occasionally threes, and then write the report together. This limits the degree to which the error reduction of a specific student can be tracked. Over the course of six reports, however, this should give a reasonable indication of increasing control. For ease of analysis, errors have been grouped into those which affect the accurate representation of content (verb form, tense, and voice, shown in Figure 2, and articles - shown in Figure 3) and those which have greater impact on the writer's interpersonal positioning (strength of claim and selfmention - Shown in Figure 4).

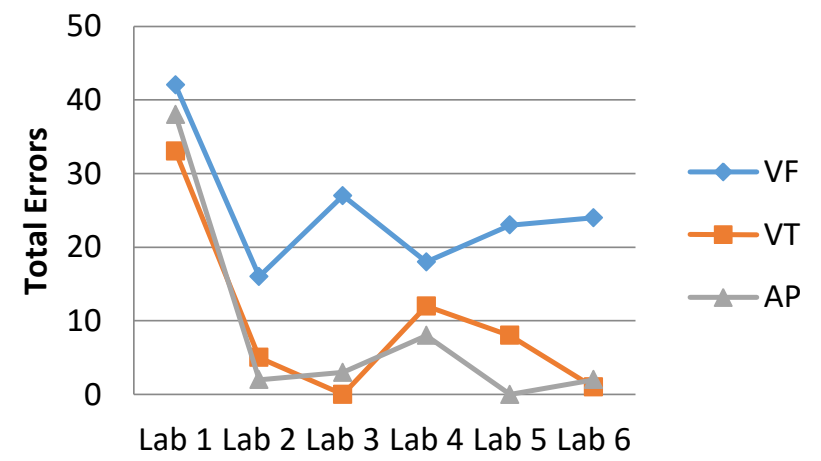

Figure 2: Frequency of verb tense (VT), verb form (VF), and passive voice (AP) errors over the 6 lab reports. The number of errors represents the sum of the occurences of this error type across the reports of the seven randomly selected students. 
Figure 2 shows a reduction in all error types, with the most significant decrease coming between reports 1 and 2 , possibly due to the teaching and learning activities associated with lab reports during this period. Report 1 represents a first attempt. By report 2 the students have studied particular language features associated with reports and been alerted to some of the most frequent errors encountered when grading report 1 . The uptick in verb tense and passive voice errors in report 4 may be attributed to the writing schedule. Reports 1 to 3 were all written in a five week period in term 1 . There was then a three month period without any language feedback before submission of report 4 in term 2 (although five reports are written each term, only three are submitted for language assessment). As mentioned above, verb tense and use of the active voice are not necessarily wrong when annotated as errors, just inappropriately used. It is possible that, without explicit language feedback, the students regressed to some extent, perhaps due to their relative lack of experience with this genre. Although by report 6 verb tense and passive voice errors have fallen to virtually zero, verb form errors persist. This could suggest a focus for future analysis of this error type, and for greater intervention in teaching.

By contrast, the frequency of the 'ART' (article) error type, shown in Figure 3, referring primarily to the incorrect use of definite (the), indefinite (a/an) and zero articles, displays a more erratic pattern. This language feature was specifically taught in class in light of the difficulties that English as an additional language writers typically display with articles, and the importance of 'the' especially in academic writing as a component of complex noun groups and as an important resource for controlling cohesion over a longer stretch of text. The sharp increase in article errors for lab 5, although unusual, is attributable to only two out of the six writers analyzed (data not explicitly shown) and could therefore be a consequence of the small sample size, or it could indicate that this is a particularly tenacious error type and that progress is not linear.

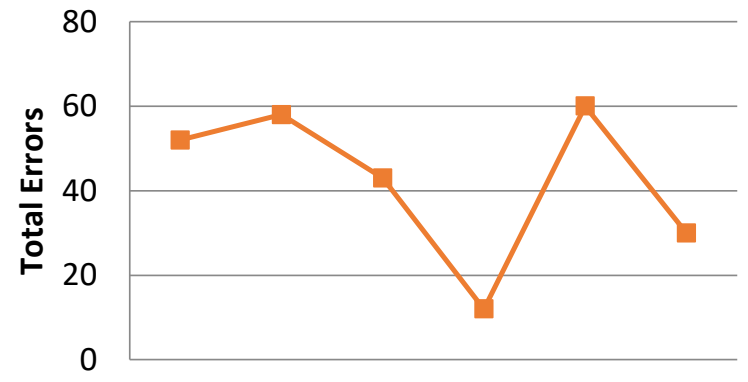

Lab 1 Lab 2 Lab 3 Lab 4 Lab 5 Lab 6

Figure 3: Frequency of article errors over the 6 lab reports. The number of errors represents the sum of the occurences of this error type across the reports of the seven randomly selected students.
As shown in Figure 4, a significant and sustained reduction in both strength of claim and self-mention errors is observed after the first report. Such a fast and sustained reduction may suggest that the students already have reasonable linguistic control of modality and clausal syntax and required practice only in the appropriate use of these features in this particular genre.

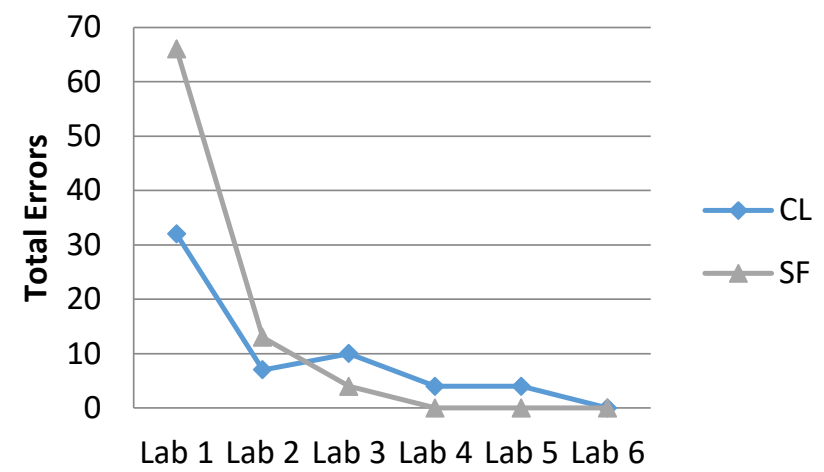

Figure 4: Frequency of article errors over the 6 lab reports. The number of errors represents the sum of the occurences of this error type across the reports of the seven randomly selected students.

The general decrease in the frequency of error types and the sustained increased in overall grades from one report to the next suggest that this particular integrated approach is quite effective at training students in lab report-specific writing conventions.

\subsection{Student Perceptions}

At the end of term 1 the students were asked to participate in a survey to help the instructors monitor reaction to the language focus of the dedicated language course and the value which they attached, as engineering students, to developing academic writing ability in English. Seventy students completed the survey out of a total cohort of 88 , and the survey was anonymously completed online during class time. Student responses relating their perception of the value of the error code language-oriented feedback and revision process are shown in Figure 5. Although the teaching, learning, and assessment activities in the dedicated language class are focused largely on the very specific generic requirements of the lab report, $73 \%$ of respondents perceive that the class helps with their general academic writing ability (with $76 \%$ reporting it helped develop writing abilities related to lab reports specifically). This suggests some degree of transfer of writing ability developed in this specific academic purposes course to the students' foundational academic writing course and wider still, to the writing requirements of their content courses. This transfer is encouraged by, for example, the language 
instructor making explicit links between the adjunct and foundational courses and highlighting the language and writing features which can be used in both. A significant minority of $9 \%$ either disagreed or strongly disagreed that such feedback was valuable. This aligns with other survey data, not presented here but presented in other work that showed a small number of students didn't perceive writing to be important for engineers [8]. In contrast, it could be that some students perceive themselves to be competent writers already and therefore learning little. It must be acknowledged too that difficulties may exist in understanding the nature of the feedback given, restricted as it is to error codes [2].

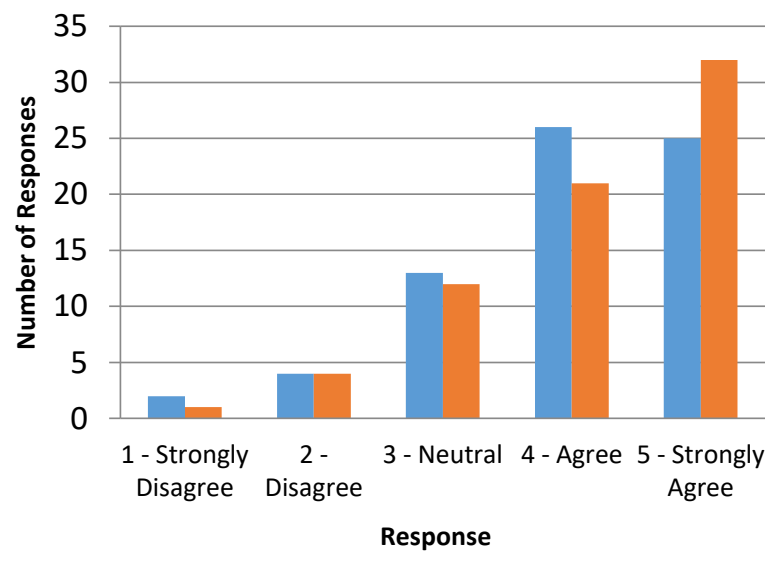

- General Academic Writing Ability

Ability to Write Lab Reports

Figure 5: Responses to a 5-point Likert scale questions asking students to indicate their level of agreement with the statement '[The error code and revision process] helps me improve my (variable)'.
This paper focuses on the effectiveness of the errorcoding and revision process for the development of writing skills associated with the lab report genre, but this process was only one type of language task given to students as part of the language course associated with the engineering chemistry courses. To gauge which activities were perceived to be the most useful to students, students were also asked which of the activities they found the most effective, and the results are shown in Figure 6. Given the motivation to improve grades by reducing the number of errors in both first draft and revision, it is not unexpected that the students saw the most value in activities that helped them to practice error identification and correction. During the first term the error coding system was introduced and examples of typical errors types were presented; students then practiced finding and correcting errors in a synthetic report - one with errors created by the instructor - before moving on to correction of authentic errors in reports produced by previous cohorts, their peers, and finally their own reports (with instructor support). The data in figure 6 also shows that the students found value in learning about lab report structure and close reading of sample reports, which was again not surprising since this is a new genre to most of them, and presented tangible, straightforward methods to increase their grades.

\section{CONCLUSIONS}

The results presented in this paper suggest that the type of language intervention described leads to a sustained improvement in lab report-related writing skills in several key error types. This is supported both by objective tracking of the frequency of common error types over two terms, and by students self-reporting this type of intervention helped them develop relevant skills. This

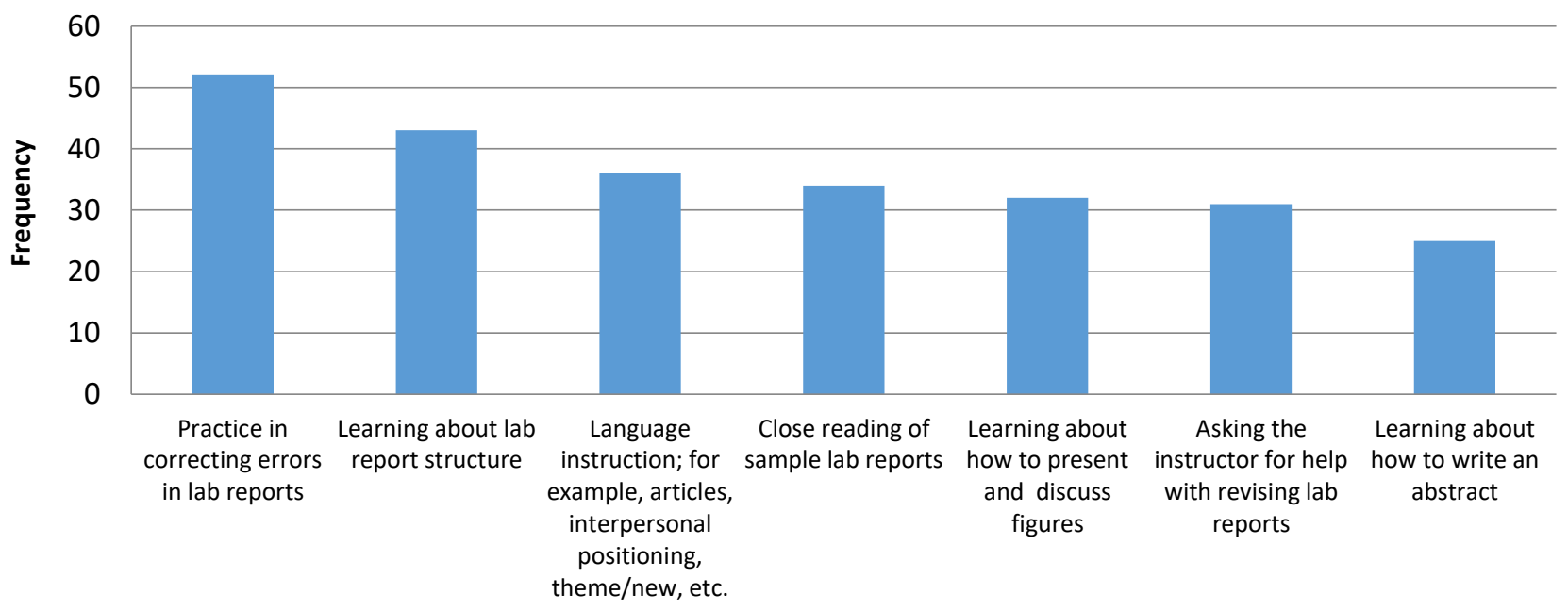

Figure 6: Answers to the open checkbox question 'Which [class] activities did you find most useful?' 
type of data further supports the conclusions reported in previous work about the integration of engineering and language content helping students improve not only their communication skills, but also their understanding of the technical content in the engineering courses [6,7].

\section{Acknowledgements}

The authors would like to express their gratitude to their colleagues at Vantage College, particularly in the Applied Science and English for Academic Purposes programs, for their ongoing support of and interest in this work.

\section{References}

[1] Edward Crawley, Johan Malmqvist, Sören Östlund, and Doris Brodeur, Rethinking Engineering Education: The CDIO Approach. New York, NY: Springer, 2010 (2nd ed.), 300 pp. \{ISBN: 978-144194260-9\}

[2] Dana R. Ferris, Treatment of Error in Second Language Student Writing, $2^{\text {nd }}$ ed. Ann Arbor: The University of Michigan Press, 2011.

[3] Ashleigh J. Fletcher, Abdul Wadood Sharif, and Mark D. Haw, "Using the perceptions of chemical engineering students and graduates to develop employability skills," Ed. Chem. Eng, vol. 18, pp. 11$25,2017$.
[4] Ken Hyland, Disciplinary Discourses: Social Interactions in Academic Writing. Ann Arbor: The University of Michigan Press, p. 13, 2013.

[5] Mona Itani and Issam Srour, "Engineering Students' Perceptions of Soft Skills, Industry Expectations, and Career Aspirations," J. Prof. Issues Eng. Ed. Practice, vol. 142, no. 1, January 2016.

[6] Mike Murphy and Gabriel Potvin. "Building Bridges: An Approach to the Integration of English Language Education in First-Year Applied Science Courses for International Students" in Proc. 2016 Canadian Engineering Education Association (CEEA16) Conf. (Halifax, NS, June 19-22, 2016), paper 10.

[7] Mike Murphy and Gabriel Potvin. "Language as an Engineering Learning Tool: Integration of Language and Engineering Education for First-Year Students to Improve both Technical Learning Outcomes and Communication Skills" in Proc. 2017 Canadian Engineering Education Association (CEEA17) Conf. (Toronto, ON, June 4-7, 2017), paper 11.

[8] John Pringle and Gabriel Potvin. "International Engineering Student Motivation to Develop Communication Skills: a Case for an Integrated Training Approach" Proc. 2018 American Society of Engineering Education (ASEE) Conf. (Salt Lake City, Utah, June 24-27, 2018), paper 21632. 